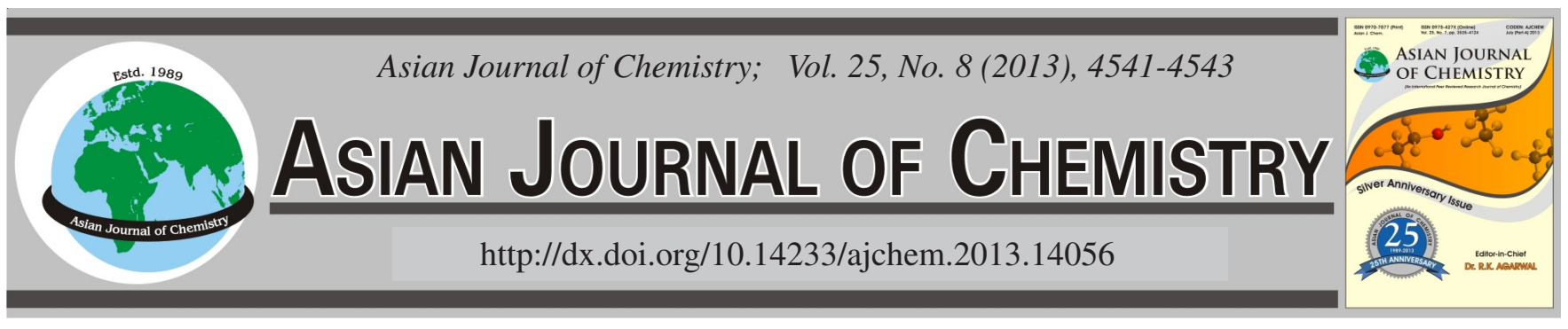

\title{
Synthesis and Fungicidal Activity of 2-(3-Fluorophenylcarbamoyl)phenyl acetate
}

Hui Feng, Chixiang Zhang, Jia Liu, Pengcheng Tang, Yuanmou Tang, Xiaorong Tang and Shirong Jiao*

School of Bioengineering, Xihua University, Chengdu 610039, P.R. China

*Corresponding author: Tel: +86 13882002899; E-mail: huif2010@163.com

In the present study, 2-(3-Fluorophenylcarbamoyl)phenyl acetate was synthesized by the ammonolysis of 2-(chlorocarbonyl)phenyl acetate. Its structure was confirmed by IR and ${ }^{1} \mathrm{H}$ NMR. Its antifungal activity against Sclerotinia sclerotiorum and Cochliobolus heterostrophus Drechsler has been determined. The results showed that it had good antifungal activity against the two different pathogenic fungi of plants. Its median effective concentrations $\left(\mathrm{EC}_{50}\right)$ reached 8.3 and $0.9 \mathrm{mg} \mathrm{L}^{-1}$, respectively.

Key Words: Synthesis, Antifungal activity, 2-(3-Fluorophenylcarbamoyl)phenyl acetate.

\section{INTRODUCTION}

Sclerotinia sclerotiorum is an important disease of cole ${ }^{1}$. In recent years by the cultivation, management condition, variety resistance and climate factors, Sclerotinia sclerotiorum damage happened already quite common. For a long period, benzimidazole fungicides have been mostly used to control it. However, in recent years, it has developed resistance to them ${ }^{2-6}$.

Similarly, Cochliobolus heterostrophus Drechsler is a pathogenic fungus of corn, It caused great harmfulness and strong infectivity. Corn under production and quality decline are mainly caused by $\mathrm{it}^{7-9}$.

Over the past decades, synthetic fungicides including carbendazim have been used to control it. Nevertheless, the development of its resistance to all these fungicides has reduced the efficacy of fungicidal treatment ${ }^{10-16}$. Thus, new fungicides are continually necessary.

Salicylic acid is a natural compound existing in many plants. It can help plants to disease resistance ${ }^{17-25}$. Its structure is simple and its chemical synthesis is easy. Therefore, 2-(3fluorophenylcarbamoyl)phenyl acetate was synthesized based on it. Meanwhile, its antifungal activity has been evaluated in the laboratory to find novel fungicides with high effect and low toxicity.

\section{EXPERIMENTAL}

Sclerotinia sclerotiorum and Cochliobolus heterostrophus Drechsler were obtained from the Chinese Academy of Agricultural Sciences. They were preserved at $4{ }^{\circ} \mathrm{C}$. All chemicals and solvents were purchased from commercial sources unless specified otherwise. IR spectra were recorded on a Thermofisher
Nicolet-6700 spectrophotometer. ${ }^{1} \mathrm{H}$ NMR spectra were taken on a Varian Unity Inova-400 instrument using deuteronchloroform as the solvent.

Synthesis of target compound: The target compound was synthesized according to the route shown in Fig. 1 and their yield was not optimized. 3-Fluoro aniline or its derivatives $(30 \mathrm{mmol})$ and pyridine $(30 \mathrm{mmol})$ were dissolved in $\mathrm{CH}_{2} \mathrm{Cl}_{2}(10 \mathrm{~mL})$. The mixture was stirred and heated to $30^{\circ} \mathrm{C}$. 2-(Chlorocarbonyl)phenyl acetate $(30 \mathrm{mmol})$ were dissolved in $\mathrm{CH}_{2} \mathrm{Cl}_{2}(10 \mathrm{~mL})$ and was slowly to the mixture under stirring 3-5 $\mathrm{h}$ until the reaction was complete. The precipitate was filtered and washed with distilled water. The pure compound was obtained by re-crystallization in anhydrous ethanol.

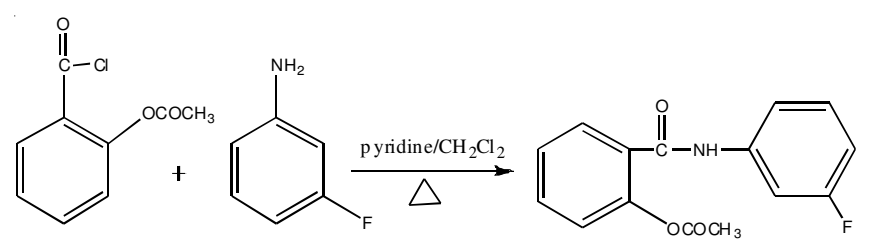

Fig. 1. Synthetic method of 2-(3-fluorophenylcarbamoyl) phenylacetate

The synthesized compound 2-(3-fluorophenylcarbamoyl)phenyl acetate: white crystal, yield: $20 \%$, m.p. $116-117^{\circ} \mathrm{C}$; IR $\left(\mathrm{KBr}, v_{\max }, \mathrm{cm}^{-1}\right): 3296,3261,3187,3077,1770,1743$, $1666,1593,1537,1484,1450,1368,1316,1227,1162,1135$, 785, 775, 751, 696, 680, 583; ${ }^{1} \mathrm{H}$ NMR (400 MHz, $\left.\mathrm{CDCl}_{3}\right) \delta$ (ppm): $2.32(\mathrm{~s}, 3 \mathrm{H}), 7.13(\mathrm{t}, J=8.4 \mathrm{~Hz}, 2 \mathrm{H}), 7.26(\mathrm{t}, J=8.0$ $\mathrm{Hz}, 1 \mathrm{H}), 7.33$ (t, $J=8.0 \mathrm{~Hz}, 1 \mathrm{H}), 7.40(\mathrm{~d}, J=8.0 \mathrm{~Hz}, 1 \mathrm{H})$, $7.51(\mathrm{t}, J=7.2 \mathrm{~Hz}, 1 \mathrm{H}), 7.74(\mathrm{~s}, 1 \mathrm{H}), 7.79(\mathrm{~d}, J=8.0 \mathrm{~Hz}, 1 \mathrm{H})$, $8.14(\mathrm{~s}, 1 \mathrm{H})$. 
Assay of antifungal activity: The antifungal activity of the synthesized compound against Sclerotinia sclerotiorum and Cochliobolus heterostrophus Drechsler was determined using the plate growth rate method ${ }^{26}$.

The synthesized compound and carbendazim (purity $90 \%$ ) were dissolved in dimethyl sulfoxide, respectively. The two solutions were diluted into five different concentrations with distilled water, respectively. They were added to the sterile culture medium (PDA) at $45^{\circ} \mathrm{C}$, mixed to homogeneity and transferred to sterile Petri dishes to solidify. A mycelium agar disc ( $5 \mathrm{~mm}$ in diameter) of the target fungi was placed in the center of PDA plates. They were incubated at $28{ }^{\circ} \mathrm{C}$ in the dark until the target fungi used as the controls covered the surface of these plates. Control groups were treated with the corresponding solutions without the synthesized compound or carbendazim. The experiment for each concentration was replicated three times. The diameter of the fungi in the cultures was measured and the inhibition of growth was calculated according to Abbott, s formula. $\mathrm{EC}_{50}$ values were calculated with the Statistics Package for the Social Sciences (SPSS) based on probit analysis.

\section{RESULTS AND DISCUSSION}

Antifungal activity against Sclerotinia sclerotiorum: The synthesized compound was submitted to laboratorial bioassay compared with the efficient fungicide carbendazim. The results are presented in Table-1. It had good antifungal activity against Sclerotinia sclerotiorum. Its $\mathrm{EC}_{50}$ value was $8.3 \mathrm{mg} \mathrm{L}^{-1}$. The results of regressive and correlative analysis indicated that the correlation was significant between concentration and efficacy. Its correlative coefficient was 0.9643. Chi square test demonstrated that the results were reliable $\left(\chi^{2}=\right.$ 2.736, df $=3, p>0.05$ ).

Antifungal activity against Cochliobolus heterostrophus Drechsler: As shown in Table-2, the synthesized compound was subjected to laboratorial bioassay using the efficient fungicide carbendazim as the comparative standard. Its $\mathrm{EC}_{50}$ value reached $0.9 \mathrm{mg} \mathrm{L}^{-1}$. The results of regressive and correlative analysis revealed that the correlation was very significant between concentration and efficacy. The correlative coefficient was 0.9594. As for the results of Cochliobolus heterostrophus Drechsler, chi square test also showed that the results were reliable $\left(\chi^{2}=0.448, \mathrm{df}=3, p>0.05\right)$.

The target compound (2-(3-fluorophenylcarbamoyl)phenyl acetate) has been successfully synthesized by means of the ammonolysis of 2-(chlorocarbonyl)phenyl acetate and its structure has also been confirmed with the aid of IR and ${ }^{1} \mathrm{H}$ NMR.

The results of laboratory bioassay have clearly demonstrated the antifungal activity of 2-(3-fluorophenylcarbamoyl)phenyl acetate against Sclerotinia sclerotiorum and Cochliobolus heterostrophus Drechsler although its antifungal activity was inferior to the comparative standard. Therefore, on the basis of it, more derivatives may be further synthesized to survey quantitative structure-activity relationships and find novel fungicides with high effect and low toxicity as well as safety to non-target organisms. Meanwhile, these results suggested that the design and synthesis of the compound may be conducive to the antifungal activity of analogues of salicylic acid The compound is also promising in the agricultural chemistry field because its antifungal activity against the two different pathogenic fungi of plants was close to the efficient fungicide carbendazim.

However, in order to realize the industrialization of the compound as a fungicide there is large amounts of research work to be done. Its antifungal spectrum needs to be determined. Its mode of action and its safety to humans and non-target organisms also need to be further investigated.

TABLE-1

ANTIFUNGAL ACTIVITY OF 2-(3-FLUOROPHENYLCARBAMOYL)PHENYL ACETATE AGAINST Sclerotinia sclerotiorum

\begin{tabular}{|c|c|c|c|c|c|c|c|c|c|c|}
\hline & \multicolumn{5}{|c|}{ 2-(3-Flurophenylcarbamoyl)phenyl acetate } & \multicolumn{5}{|c|}{ Carbendazim } \\
\hline Concentration $\left(\mathrm{mg} \mathrm{L}^{-1}\right)$ & 25 & 12.5 & 6.3 & 1.6 & 0.9 & 50 & 25 & 12.5 & 6.3 & 3.1 \\
\hline Inhibition of growth* $(\%)$ & 91.1 & 61.4 & 36.9 & 15.7 & 5.13 & 94.1 & 85.5 & 74.9 & 61.1 & 49.5 \\
\hline Regressive equation $(Y=a X+b)$ & \multicolumn{5}{|c|}{$Y=2.4054 X+2.7838$} & \multicolumn{5}{|c|}{$\mathrm{Y}=1.2683 \mathrm{X}+4.3132$} \\
\hline $\begin{array}{l}\mathrm{EC}_{50}\left(\mathrm{mg} \mathrm{L}^{-1}\right) \\
(95 \% \mathrm{CL})\end{array}$ & \multicolumn{5}{|c|}{$\begin{array}{c}8.3 \\
(7.4-9.5)\end{array}$} & \multicolumn{5}{|c|}{$\begin{array}{c}3.5 \\
(2.3-4.6)\end{array}$} \\
\hline Correlative coefficient (r) & \multicolumn{5}{|c|}{0.9643} & \multicolumn{5}{|c|}{0.9614} \\
\hline$\chi^{2}$ & \multicolumn{5}{|c|}{2.736} & \multicolumn{5}{|c|}{0.605} \\
\hline
\end{tabular}

TABLE-2

ANTIFUNGAL ACTIVITY OF 2-(3-FLUOROPHENYLCARBAMOYL)PHENYL ACETATE AGAINST Cochliobolus heterostrophus Drechsler

\begin{tabular}{|c|c|c|c|c|c|c|c|c|c|c|}
\hline & \multicolumn{5}{|c|}{ 2-(3-Flurophenylcarbamoyl)phenyl acetate } & \multicolumn{5}{|c|}{ Carbendazim } \\
\hline Concentration $\left(\mathrm{mg} \mathrm{L}^{-1}\right)$ & 100 & 50 & 25 & 12.5 & 6.3 & 100 & 50 & 25 & 12.5 & 6.3 \\
\hline Inhibition of growth* $(\%)$ & 90.1 & 83.5 & 80.2 & 74.4 & 70.1 & 87.5 & 70.8 & 57.5 & 41.5 & 35.5 \\
\hline Regressive equation $(Y=a X+b)$ & \multicolumn{5}{|c|}{$Y=0.5972 X+4.9787$} & \multicolumn{5}{|c|}{$Y=1.2373 X+3.518$} \\
\hline $\mathrm{EC}_{50}\left(\mathrm{mg} \mathrm{L}^{-1}\right)$ & \multicolumn{5}{|c|}{0.9} & \multicolumn{5}{|c|}{15.7} \\
\hline$(95 \% \mathrm{CL})$ & \multicolumn{5}{|c|}{$(3.4-6.6)$} & \multicolumn{5}{|c|}{$(12.1-19.6)$} \\
\hline Correlative coefficient (r) & \multicolumn{5}{|c|}{0.9594} & \multicolumn{5}{|c|}{0.9808} \\
\hline$\chi^{2}$ & \multicolumn{5}{|c|}{0.448} & \multicolumn{5}{|c|}{2.862} \\
\hline
\end{tabular}

*Based on the mean of triplicates. 


\section{ACKNOWLEDGEMENTS}

This project was supported by the Scientific Research Fund of Sichuan Provincial Education Department (No. 09ZA158) and the Key Scientific Research Fund of Xihua University (No. R0820501).

\section{REFERENCES}

1. X.J. Chen, M.J. Cao, Y. Wang, Y.H. Tong and J.Y. Xu, Chin. J. Oil Crop Sci., 31, 503 (2009).

2. Y.L. Pan, Z.Y. Wang and H.Z. Wu, J. Jiangsu Agric., 13, 32 (1997).

3. Z.Q. Shi, M.G. Zhou and Z.Y. Ye, J. Jiangsu Agric., 16, 212 (2000).

4. W. Li, Y.J. Zhou and H.G. Chen, Chin. J. Oil Crop Sci., 29, 63 (2007).

5. K.Y. Liu and F.X. Chen, Anhui Agric. Sci., 35, 756 (2007).

6. R.E. Beever and H.M.R. Brien, Agric. Res., 26, 391 (1983).

7. B. Gillian Turgeon and S.E. Baker, Adv. Genet., 57, 219 (2007).

8. W.G. Kovachich, Trans. Br. Mycol. Soc., 40, 90 (1957).

9. S.A. Mabadeje, Trans. Br. Mycol. Soc., 52, 267 (1969).

10. A. Have, R. van Berloo, P. Lindhout and J.A.L. van Kan, Eur. J. Plant Pathol., 113, 153 (2007).

11. S.I. Ignatova, N.S. Gorshkova and T.A. Tereshonkova, Acta Physiol. Plant, 22, 326 (2000).
12. H. Egashira, A. Kuwashima, H. Ishiguro, K. Fukushima, T. Kaya and S. Imanishi, Acta Physiol. Plant., 22, 324 (2000).

13. R.L. Guimaraes, R.T. Chetelat and H.U. Stotz, Eur. J. Plant Pathol., 110, 13 (2004).

14. R. Finkers, P. van de Berg, R. van Berloo, A. Have, A.W. van Heusden, J.A.L. van Kan and P. Lindhout, Theor. Appl. Genet., 114, 585 (2007).

15. R. Finkers, Y.L. Bai, P. van de Berg, R. van Berloo, A. Have, J.A.L. van Kan, P. Lindhout and A.W. van Heusden, Theor. Appl. Genet., 114, 1071 (2007).

16. R. Finkers, Y.L. Bai, P. van de Berg, R. van Berloo, A. Have, J.A.L. van Kan, P. Lindhout and A.W. van Heusden, Euphytica, 159, 83 (2008).

17. J. Kovacik, B. Klejdus, J. Hedbavny and M. Backor, Ecotoxicology, 18, 544 (2009).

18. H. Karlidag, E. Yildirim and M. Turan, Sci. Agric., 66, 180 (2009).

19. M. Snyman and M.J. Cronje, J. Exp. Bot., 59, 2125 (2008).

20. H.T. Liu, Y.Y. Liu, Q.H. Pan, H.R. Yang, J.C. Zhan and W.D. Huang, J. Exp. Bot., 57, 3337 (2006).

21. S.M. Clarke, L.A.J. Mur, J.E. Wood and I.M. Scott, Plant J., 38, 432 (2004).

22. B. Singh and K. Usha, Plant Growth Regul., 39, 137 (2003)

23. M.A. E1-Tayeb, Plant Growth Regul., 45, 215 (2005).

24. H. Tachi, K. Fukuda-Yamada, T. Kojima, M. Shiraiwa and H. Takahara, Plant Physiol. Biochem., 47, 73 (2009).

25. N. Yalpani, A.J. Enyedi, J. Leon and I. Raskin, Planta, 193, 372 (1994).

26. W. Huang and G.F. Yang, Bioorg. Med. Chem., 14, 8280 (2006). 